\title{
Underwater medicine: a neglected area in Accident and Emergency specialist training
}

\author{
G. D. Braatvedt MRCP1 ${ }^{1}$ B. G. Mathew FRCS ${ }^{2}$, R. J. M. Corrall MD, FRCP' \\ ${ }_{1}^{1}$ Department of Medicine, The Royal Infirmary, Bristol, UK \\ 2 Department of Neurosurgery, Frenchay Hospital, Bristol, UK
}

We have evaluated the available medical care to sports divers by a postal questionnaire sent to consultants and senior registrars in Accident and Emergency medicine in the UK, assessing their training in underwater medicine. Replies were received from 60 of 96 consultants $(63 \%)$ and 32 of $58(55 \%)$ senior registrars. Thirty-two per cent of consultants and $50 \%$ of senior registrars had previous personal experience in managing an underwater diving accident. Thirty per cent of consultants and only $19 \%$ of senior registrars had prior formal postgraduate training in underwater medicine. Twenty-seven per cent of consultants and $13 \%$ of senior registrars replying did not know the pattern of referral for specialist advice nor where the nearest recompression chamber was to be found. We believe that more formal postgraduate training in underwater medicine is needed by $A$ and $E$ medical staff. Furthermore, clear guidelines about emergency management and patterns of referral for diving accidents should be displayed prominently in all $\mathrm{A}$ and $\mathrm{E}$ departments.

Keywords: Underwater medicine, diving accidents, training in underwater medicine

There are an estimated 50000 sports divers and 1500 commercial divers in the $\mathrm{UK}^{1}$. The medical care of commercial divers is controlled by law and specialists in diving medicine are designated to attend to their medical needs. In contrast, the care of sports divers is not supervised and they will tend to present to the nearest Accident and Emergency ( $A$ and $E$ ) unit in the event of a diving accident. Roughly 120 sports divers required recompression therapy in 1988 and the incidence appears to be rising ${ }^{2}$.

To evaluate the medical care available, we have studied by postal questionnaire the training that UK $A$ and $E$ consultants and senior registrars receive in underwater medicine. We have also investigated their knowledge of the location of specialist referral centres for further management of dysbaric illness.

\section{Methods}

Two-hundred-and-eighty-seven UK A and E departments were identified from the 1988 Directory of Emergency and Special Care Units Handbook (published by CMA Medical Data Ltd., Cambridgeshire). This

Address for correspondence: Dr G. D. Braatvedt, Department of Medicine, The Royal Infirmary, Bristol BS2 8HW, UK

(C) 1991 Butterworth-Heinemann Ltd. 0306-3674/91/020102-02
Table 1. Questionnaire

1. Give details of undergraduate teaching, postgraduate lectures, one-day seminars or courses in underwater medicine attended.

2. Do you know whom to contact when faced with a patient with a decompression accident?

3. Where is your nearest recompression chamber?

4. Give details of personal experience in managing diving accidents (other than drowning).

5. Are you a scuba diver?

excluded $\mathrm{A}$ and $\mathrm{E}$ departments in Northern Ireland and those specializing in ophthalmological, paediatric and military emergencies. Every third $A$ and $E$ department listed $(n=96)$ was chosen to receive a postal questionnaire (Table 1) addressed personally to the consultant whose name appeared first. In this handbook, the departments are listed alphabetically in districts within regions. In addition, the names and addresses of 58 senior registrars practising in $\mathrm{A}$ and $\mathrm{E}$ medicine were obtained from the Casualty Surgeons Association and the same questionnaire was sent to all of them.

In an effort to establish current trends in undergraduate teaching, the deans of 24 UK medical schools were asked how many hours of formal training the undergraduates received in underwater medicine.

\section{Results}

Sixty consultants responded (63\%) (Table 2). A total of $18(30 \%)$ had received formal postgraduate training in the form of a course (8), or a lecture or one-day seminar (14). Three consultants had had undergraduate training in underwater medicine. Nineteen responders $(32 \%)$ had previous personal experience in managing a diving accident and $16(27 \%)$ were unaware of the nearest decompression chamber or of the availability of specialist referral.

Thirty-two senior registrars responded (55\%). Only six (19\%) admitted to any formal postgraduate training; all six had attended a lecture or one-day seminar and two of these had also attended a course. Sixteen responders $(50 \%)$ answered positively to personal experience in managing a diving accident. Four responders $(13 \%)$ did not know the nearest recompression chamber site.

Eighteen of 24 medical schools replied $(75 \%)$. Three $(17 \%)$ medical schools devoted a total of $1 \mathrm{~h}$ to 
Table 2. Results of postal questionnaire to 96 consultants and 58 senior registrars on underwater medicine training

\begin{tabular}{|c|c|c|}
\hline $\begin{array}{l}\text { Training, knowledge } \\
\text { and experience }\end{array}$ & $\begin{array}{l}\text { Consultants } \\
60 \text { responders } \\
\text { (63\%) }\end{array}$ & $\begin{array}{l}\text { Senior registrars } \\
32 \text { responders } \\
\text { (55\%) }\end{array}$ \\
\hline $\begin{array}{l}\text { Undergraduate training } \\
\text { Postgraduate training }\end{array}$ & $\begin{array}{c}3(5) \\
18(30) \\
\text { (70\% in post } \\
<10 \text { years) }\end{array}$ & $\begin{array}{l}3(9) \\
6(19)\end{array}$ \\
\hline $\begin{array}{l}\text { Lecture or seminar } \\
\text { Postgraduate course }\end{array}$ & $\begin{array}{c}14(23) \\
8(13) \\
\text { (Three while in } \\
\text { armed forces) }\end{array}$ & $\begin{array}{c}6(19) \\
2(6) \\
\text { (One while in } \\
\text { armed forces) }\end{array}$ \\
\hline $\begin{array}{l}\text { Referral pattern not } \\
\text { known }\end{array}$ & $16(27)$ & $4(13)$ \\
\hline $\begin{array}{l}\text { Personal experience in } \\
\text { managing a diving } \\
\text { accident }\end{array}$ & $\begin{array}{l}19(32) \\
\text { (Nine with no } \\
\text { previous } \\
\text { training) }\end{array}$ & $\begin{array}{c}16(50) \\
\text { (Ten with no } \\
\text { previous } \\
\text { training) }\end{array}$ \\
\hline Scuba divers & $3(5)$ & $7(22)$ \\
\hline
\end{tabular}

Values in parentheses are percentages

the teaching of underwater medicine to undergraduates. Fourteen $(\mathbf{7 8 \%})$ had no time set aside for this purpose and one medical school refused to answer the question.

\section{Discussion}

Although constituting a relatively rare presentation to $A$ and $E$ departments, dysbaric illness is an important condition to diagnose since its treatment is often worthwhile and delay beyond a few hours may adversely effect the prognosis ${ }^{3}$. It usually presents as pulmonary barotrauma (pneumothorax, mediastinal emphysema or arterial air embolism) or as decompression sickness involving joints or skin (type 1), or spinal cord, cerebrum or cerebellum (type 2). In their classic forms, all are readily recognized. However, many cases present with vague symptoms such as abdominal pain, fatigue or tingling, which may herald catastrophic spinal cord damage. Recent evidence suggests that the majority of cases of decompression sickness clinically confined to the spinal cord also have cerebral perfusion defects and, therefore, must be regarded as having multisystem disease ${ }^{4}$. Decompression sickness can occur despite safe diving practice and use of decompression tables, and pulmonary barotrauma can even occur in the swimming pool if divers using compressed air cylinders hold their breath on ascent ${ }^{\mathbf{1}}$. Thus it is imperative that, confronted with divers who are symptomatic within $24 \mathrm{~h}$ of a dive, doctors should consider dysbarism and act appropriately.

The lack of teaching of underwater medicine at undergraduate level is perhaps not surprising in view of competition for space in an already packed curriculum. However, only $30 \%$ of consultants and $19 \%$ of senior registrars in the $A$ and $E$ departments surveyed had any formal postgraduate training in underwater medicine. The finding, however, that $32 \%$ of consultants and $50 \%$ of senior registrars had personal experience in managing a diving accident indicates that formal training at postgraduate level should be mandatory for those embarking on a career in $\mathrm{A}$ and $\mathrm{E}$ medicine. Of great concern is the finding that roughly $25 \%$ of consultants and $13 \%$ of senior registrars were unaware of the locality of specialist referral centres, a deficiency that clearly should be rapidly rectified.

\section{References}

1 Douglas JDM. Medical problems of sport diving Br Med J 1985; 291: 1244-6.

2 Diving Incidence Report. London: British Sub-Aqua Club, 1988

3 McIver NKI. Treatment of compressed-air decompression accidents. J R Soc Med 1989; 82: 74-9.

4 Adkisson GH, Macleod MA, Hodgson $M$ et al. Cerebral perfusion deficits in dysbaric illness. Lancet 1989; ii: 119-22.

\section{Appendix 1. RECOMPRESSION CHAMBERS}

Extensive facilities are available for helping with cases of dysbaric illness

Fifteen chambers under Ministry of Defence control operate in the UK. A further 14 chambers operate under civilian control. The addresses of these chambers are available from the British Sub-Aqua Club, 16 Upper Woburn Place, London WC1 0QW, UK.

Twenty-four hour specialist advice in managing diving accidents is available through the Royal Navy at Portsmouth (telephone 0705822351 (for general advice) or 070581888 (FOR A LIFE THREATENING EMERGENCY ONLY), ext. 24875 during working hours, or ext. 22008 after hours). The Coastguard or Police can arrange for emergency transport if needed.

\section{Appendix 2. FIRST AID TREATMENT FOR DYSBARIC ILLNESS}

- $100 \%$ face mask oxygen

- Supine (head down and left lateral position if cerebral air embolism)

- Intravenous fluids (crystalloid or dextran - beware anaphylaxis) $)^{3}$

- Intercostal chest drain if pneumothorax

- Catheterize if serious decompression sickness

- No analgesics without expert advice (especially those containing nitrogen such as Entonox)

- Intravenous heparin and steroids are controversial seek advice

- Urgently contact Portsmouth Royal Navy (0705 822351 or 0705818888 ) for specialist advice

- Arrange transport to recompression chamber (low altitude if using helicopter). 